\title{
COMMISSION 5: DOCUMENTATION AND ASTRONOMICAL DATA DOCUMENTATIONS ET DONNEES ASTRONOMIQUES
}

\author{
PRESIDENT: G. A. Wi $1 \mathrm{kins}$
}

Report of Meetings at Buenos Aires: July 1991

Session 1 .

26 July 1991

$09.00-10.30$

BUSINESS MEETING

Chairman: G. A. Wilkins

1. Introduction. The President opened the meeting by reviewing the agenda and the schedule of the meetings of the Commission. He regretted that it would be not be possible to hold a second business meeting towards the end of the Assembly to allow for a review of the future organisation and programme of the Commission after the discussions of the coming week. [This report includes some details that were actually decided at later meetings.] He noted that the chairmen of three of the working groups were not present in Buenos Aires, and so he would chair the meetings concerned. He also drew attention the Joint Commission Meeting on the archiving of current observational data; this meeting had been initiated by the Commission, but it involved many other Commissions. [Unfortunately, owing to the fire in the basement of the San Martin Centre on 31 July, this meeting had to be cancelled, although the papers will be published in Highlights of Astronomy.] The total attendance at the meeting was 23, including 11 members, 1 consultant, 9 nominees for membership and 2 others.

2. Report of the President for 1988-1991. The President noted that his report or the period 1 November 1987 to 30 June 1990 had been published in Trans. IAU $21 \mathrm{~A}, 7-12$, and that an updated version had been distributed widely in the Commission's Newsletter No.5 earlier in the month. He expressed his gratitude to the Vice-President, B. Hauck, who had agreed to distribute the Newsletter at short notice when it was unexpectedly found that the Royal Greenwich Observatory would not distribute it. In general, the levels of activity of the working groups had been fairly low but, as the following reports on the specialised meetings show, useful progress has been made on many of the projects. The President expressed his thanks to all those who had contributed to the work of the Commission during the past 6 years, and especially to the Vice-President, the chairmen of working and task groups, and the other members of the Organising Committee.

3. Working Groups for 1991-1994. It was agreed that the following working groups and task groups should be continued, with a change of chairman in some cases.

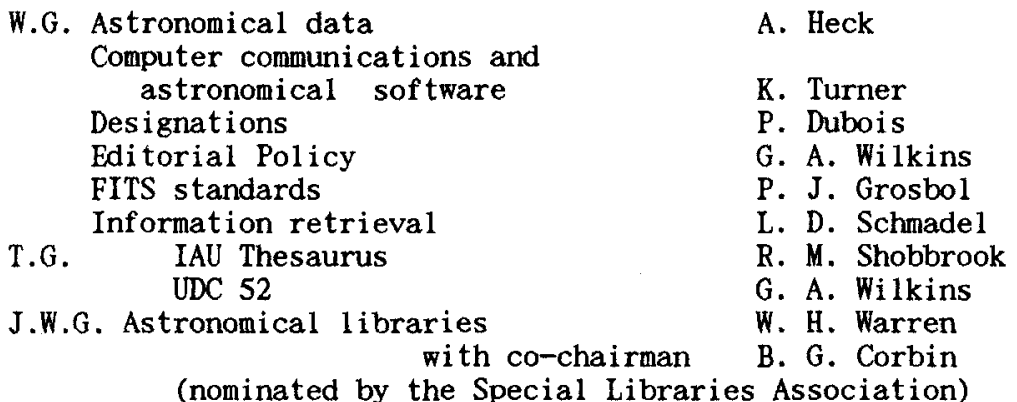

In addition it was agreed that, in accordance with the wishes of the IAU Executive Committee, there should be a new Working Group that would be made up of representatives of the principal international data centres. It proved to be impracticable to set up this working group at Buenos Aires, and so C. Jaschek will act as convenor of a meeting that will adopt a constitution and elect the chairman of the Group. 
The Commission was invited to nominate a representative on the new IAU Working Group on standards for astronomical reference systems; it was agreed that this would be appropriate and that $G$. Kaplan would be the Commission's nominee. It was also agreed that the Commission should participate in the Commission 41 Working Group on the preservation of astronomical documents; B. Hauck will be a member of the Group, one of whose objectives will be to set up an international registry of astronomical archives of historical interest that are held at astronomical institutions.

4. Officers and Organising Committee for 1991-1994. It was agreed that the officers for the coming triennium should be:

President: B. Hauck Vice-President: O. B. Dluzhnevskaya

It is customary for the President of Commission 5, which is regarded as a subcommittee of the IAU Executive Committee, to serve for two terms.

It was also agreed that the chairmen of the working groups should be members of the Organising Committee; the complete list is:

M. Creze, P. Dubois, P. J. Grosbol, A. Heck, Li Qibin, J. M. Mead,

L. D. Schmade1, K. Turner, W. H. Warren, G. Westerhout, G. A. Wilkins.

It may be noted that Gart Westerhout was added to the list in the recognition of his past major contributions to the work of the Commission and in the expectation that he will continue to be one of its most active members.

5. New members and consultants. The following persons will (subject to confirmation by the IAU Secretariat) become members of the Commission:

H. Andernach, M. A. Albrecht, P. Alvarez, Y. Chu, B. Cogan, M. Creze,

G. Helou, A. S. Kharin, Li Qibin, P. Linde, L. S. Lyubimbov, S. M. Matz,

G. Pature1, G. Riegler, S. Roessiger, V. I. Sczipnichenko, A. P. G. Serrano,

A. G. Sokolsky, K. Turner, M. Tsvetkov, R. Wielen, Wu Zhiren.

The following persons will be invited to be consultants for the coming triennium:

S. Borde, E. Bouton, B. Corbin, H. Knudsen, M. Kurtz, S. Laloe,

D. Lubowich, W. Luck, A. Ratnakar, R. M. Shobbrook, M. Vargha.

6. Resolutions. The Commission adopted three resolutions, which are briefly summarised as follows; the full texts are given with the report of the General Assembly.

1. That support be provided to experts for the compilation of catalogues of critically evaluated data.

2. That a directory of astronomical software for general use should be compiled and maintained.

3. That editors of astronomical journals should include in their instructions to authors the IAU recommendations on the use of SI units, the designation of celestial objects, and the abbreviations for the titles of journals.

In addition, the Commission agreed to support the proposal to Commission 41 on the establishment of a register of astronomical archives of historical interest.

7. Terms of reference. The President pointed out that it is the policy of the Union that each commission should have an agreed set of terms of reference and rules of procedure. As a step towards this he put forward the following statement of the role of the Commission, which he had prepared for presentation at the meeting of the IAU Working Group on the Worldwide Development of Astronomy.

"The principal objective of Commission 5 is to improve and extend the flow of information to and within the astronomical community. The Commission provides advice to the IAU Executive Committee and carries out the following principal activities in support of this objective: 
1. The development of standards and techniques for the dissemination, archiving and retrieval of information.

2. The organisation of cooperative activities relating to information that is published in printed form or made available in electronic, magnetic, or opticaldisc formats."

It was agreed that this statement should be used pending further consideration.

8. Future meetings. The President put forward the view that working groups were more productive, and cooperative activities were more successful, when those taking part were able to meet between assemblies. The members and consultants should look out for, and draw attention to, conferences where it might be appropriate to hold 'splinter' meetings relating to the Commission's activities before the next General Assembly; this is particularly desirable as many members had been unable to attend this meeting.

9. Other business. A. Serrano suggested that the editor of the daily newspaper of the Assembly be asked to include a note to encourage participants to make known their e-mail addresses to the IAU Office and to the Chairman of the Working Group on Computer communications. [This was not done, but such a note could be included in the IAU Information Bulletin.] There being no other business, the President closed the meeting after thanking those present for their participation.

Sessions $2 \& 3$.

1. Introduction. The Chairman of the Working Group on Astronomical Data, Gart Westerhout, opened the meeting by reviewing the agenda. At least 30 members and other participants were present. Much detail has had to be omitted from the following report, but an extended report is given in the Newsletter No. 3, dated 20 August 1991, that has been prepared and distributed by the Chairman.

2. Officers and membership. After a short discussion the officers and organising committee for the coming triennium were appointed:

Chai rman: Andre Heck; Vice-Chai rman: Jaylee Mead;

Organising Committee: L. Benacchio, M. Creze, O. B. Dluzhnevskaya,

P. J. Grosbo1, B. Hauck, G. Lynga, S. Nishimura, W. H. Warren.

Several new members were approved, bringing the total membership to 52 .

3. Reports from data centres. The Chairman read the report by 0 . Dluzhnevskaya on the data centre in Moscow. M. Creze presented his report on the CDS in Strasbourg, and drew particular attention to the improved facilities and increased usage of SIMBAD; he also paid tribute to the work of his predecessor, Carlos Jaschek, who had initiated the CDS and encouraged the development of regional data centres in other countries. W. H. Warren reported on the NASA/GSFC centre. A CD-ROM disc containing 31 catalogues had been prepared and distributed successfully; a two-disc set containing 114 catalogues has since been prepared with IAU support. The on-line system now allows direct file transfers. Li Qibin reported on the Chinese astronomical data centre in Beijing; he plans to organise a workshop on data centres in 1992. The Chairman distributed a report provided by B. Madore on the services available from the NASA/JPL Extra-galactic Database (NED). T Spoelstra reported that all the radio data from the Westerbork Synthesis Telescope (since 1970) are now available in computer-readable form.

During the discussion, concern was expressed that the costs of access to some data centres, including SIMBAD, made it impossible for astronomers in some countries (for example, those with hard-currency restrictions) to make use of the facilities. Creze pointed out that SIMBAD had been developed by a small research institute; he hoped to obtain more support from the major user countries so that 
access charges could be waived for small users, who would still have to pay their own telecommunication charges. It was agreed that the IAU should request data centres to provide free access for astronomers in developing countries; it was subsequently decided that the chairman should write on behalf of the Working Group, and he has done this.

4. New Working Group on Data Centres. C. Jaschek stated that he had proposed the setting up of a Federation of Astronomical Data Centres and Data Services, and he outlined the aims of such a federation. The IAU Executive Committee had, however, suggested that it would be more appropriate to set up within Commission 5 a new working group whose members would be representatives of the major organisations that provide data services to the international community. It proved to be impossible to hold a meeting of representatives during the General Assembly, and so Jaschek will convene a meeting at which his proposal may be discussed and, if it is adopted, the objectives and structure may be agreed and the officers of the Group may be elected. The matter will then be considered by the President of the Commission.

5. FITS standards. P. Grosbol, the chairman of the FITS Working Group, reported that a comprehensive document on the FITS standards (for data on images) is being prepared by the NASA Standards of $\mathrm{fice}$. The draft is under study, and the $\mathrm{f}$ inal version will be subject to approval by the IAU Working Group.

6. Data on radio sources. H. Andernach drew attention to the lack of a proper archive of radio-source data. He has started to systematically collect such data, and Commission 40 has set up a working group on 'archiving and databases for radio astronomy'. During the discussion it was pointed out that existing data centres could assist in the distribution of the final database, but they did not have the expertise for its compilation.

7. Long-term cataloguing projects. M. Barbier made an impassioned plea for the support of long-term cataloguing projects, and gave as an example her own work on the compilation of a catalogue of radial velocities. Such 'routine' projects require considerable expertise, but it is difficult to get adequate support as reseach grants are usually only given when results can be expected inmediately. After discussion, a resolution urging that support be given to such projects was adopted; this resolution was subsequently endorsed by Commission 5 and by the General Assembly.

8. Astronomical sof tware. S. West, on behalf of $T$. Banks, announced the availability of an archive of computer software for the analysis of data on variable stars at the Victoria University of Wellington, New Zealand. This led to a discussion on the problems of such archives: for example, who is responsible for the quality and maintenance of the code and of its documentation? Eventually, it was generally agreed that a directory of sof tware is more useful than an archive, so that users can contact directly the person(s), or the organisation, responsible for the original software or for its subsequent development and distribution. C. R. Benn had started to compile such a directory as part of the activities of the Working Group on Computer Communications and Sof tware (see report on the joint session with Commission 6), and the matter is being considered by a working group of the American Astronomical Society; it was suggested that NASA's Astrophysics Data System would be ideally suited to house such a directory. It was agreed to submit a resolution endorsing the establishment and maintenance of a software directory service.

9. Electronic mail. There was a short discussion on the usefulness of directories of the e-mail addresses, and on the problems associated with their compilation, maintenance and unwanted use for "junk-mail". This topic was discussed again at a joint session with Commission 6, and $\mathrm{K}$. Turner was appointed chairman of the Working Group on Computer communications and astronomical sof tware. 
10. Other matters. The Chairman drew attention to the relevance of CODATA activities to astronomy. $R$ Hanisch mentioned that the Space Telescope Science Institute is plannng to make Palomar-plate scans available on CD-ROMs. The Chairman was thanked for his work on behalf of the Group during the past six years.

Session 4.

27 July 1991

$09.00-10.30$

DESIGNATION OF ASTRONOMICAL OBJECTS

Chairman: F. Spite

1. Preliminaries. The Chairman considered that it was time for him to retire from chairmanship of the Working Group on Designations, and it was agreed that P. Dubois should be the Chairman for the next triennium. The membership of the Group was reviewed and is now: H. E. Bond, K. S. de Boer, T. E. Corbin, H. R. Dickel, O. B. Dluzhnevskaya, G. Helou, P. W. Hodge, C. Jaschek, M.-C. Lortet, J. M. Mead, J.-C. Mermilliod, F. Ochsenbein, G. Paturel, F. Spite and W. H. Warren. Any of these members may be consulted if there is any doubt about the designation of newly discovered sources outside the Solar System.

2. Report on progress. The Chairman reported that the summary of the 'main guidelines' had been published recently by several journals with their instructions to authors; it has the title Specifications concerning names, designations and nomenclature for astronomical radiation sources outside the Solar System. It was also sent to the presidents of the commissions of the IAU for comment. In addition, the list of current abbreviations and acronyms for catalogues and lists has been made available on-line to users of the SIMBAD database, and will be accessible early in 1992 at the Paris Observatory by e-mail (contact S. Borde). Two papers by S. Borde and M. -C. Lortet to be published in Inf. BuIl. CDS give the current status of the list. H. Dickel has reported to Commission 34 on work on the designation of compl icated sources.

3. New actions. The text of the 'Specifications' summary was modified in the light of comments received from commission presidents and others. It was agreed that a very short summary of this summary should be prepared; it would contain references to the publication of the full summary so that editors could publish it regularly to remind authors and referees of the importance of the use of unambiguous designations. Further efforts will be made to encourage authors (and data centres) to ensure that all new lists of objects satisfy the guidelines and observatories to register carefully the designations of all objects that are observed; a short document on this matter is to be prepared and distributed to all observatories.

Further thought must be given to finer details, such as: precise formats for machine-readable 1ists, including the coding of exponents and indices, the use of separators and concatenators, and the handling of insertions; the designation of sub-components, of stars in clusters, of complicated sources, and of overlapping sources; and the identification of sources seen in different wavelengths. The Working Group would welcome suggestions on these matters so that the guidelines may be extended appropriately.

Session 5.

29 July 1991

$14.00-15.30$

EDITORIAL POLICY

Chairman: G. A. Wilkins

1. Introduction. The Chairman apologised for the absence of the Chairman of the Working Group on Editorial Policy, P. A. Wayman, and for the lack of a report on the activities of the Group. He expressed his disappointment at the lack of clear progress in the adoption by the astronomical community of the resolution on publications that was adopted at the last IAU General Assembly. He drew attention to the availability (without charge) of the IAU Style Manual from the IAU office in Paris and to the summary that was reprinted in IAU Information Bulletin 65 (January 1991). He stated that he would be the next chairman of the working group, and that 
he would be glad to hear from persons who would would be willing to participate in its activities. He saw the main tasks as being the improvement of the Style Manual and the continuation of the attempts to get its recommendations adopted more widely. The meeting was attended by (at least) 8 members of the Commisssion and 9 other participants.

2. The Style Manual. The main concerns that were expressed during the review of the Style Manual related to the reluctance of many (senior) astronomers to use SI units, even though they are very widely taught in schools and colleges and are obligatory in many fields of science and technology, and to the difficulties in making the recommendations on designations better known and more widely used. (The latter topic was discussed in greater depth at session 4.) It was suggested that efforts should be made to persuade the producers of major databases to use SI units. W. H. Warren drew attention to the need for standard abbreviations for special characters, such as Greek letters, for use in electronic communications of data and texts.

J.-C. Pecker considered that a French translation of the Style Manual should be made since French is an official language of the Union. He also felt that translations into other languages would be useful as the advice and recommendations are largely independent of the language of publication.

3. Use of TEX and related systems. R. Hanisch reviewed recent developments in the growing use of TEX and LATEX in conjunction with style files, such as AASTEX and SPACEKAP, for the submission of papers for publication. This technique also allows papers to be distributed by electronic-mail and to be archived in computer databases. It was agreed that authors should not be expected to deal with typesetting details, such as the choice of fonts. The IAU Style Manual should include guidance on the use of such systems.

Session 6.

1. Preliminaries. The Chairman gave the apologies of the Chairman of the Working Group on Information Retrieval, L. D. Schmadel, for his absence and stated that he had received a report from him. Schmadel will continue as Chairman of the Group, but he would appreciate more help from members of the Commission; he hopes to work more closely with the working groups on designations and astronomical data. The total attendance was 22, of whom at least 9 were members of Commission 5.

2. Abstracting services. Astronomy and Astrophysics Abstracts (AAA) has continued to appear regularly; much of the information given in the printed volumes will be incorporated into the on-line database PHYS of the Fachinformationszentrum at Karlsruhe. A new edition of a booklet with the title "User Aids: Astronony and Astrophysics" has been published as no. 3-9 in the Phys Database Reference Series (ISSN 0721-5274). The IAU Vocabulary of astronomical terms will not after all be published in the information bulletin of the Strasbourg data centre since it may be superseded by the IAU Thesaurus. It was noted that the editors of several of the leading astronomical journals have issued a common list of terms to be used for subject headings in their indexes.

3. IAU Thesaurus. B. Corbin presented the report of the Chairman of the Task Group on the IAU Thesaurus on behalf of $R$. M. Shobbrook, who was unable to attend. Version 3 of the thesaurus has been compiled, but further detailed checking will be carried out before it is issued. The chairman also presented a brief report by $W$. Liick on the checks that he and Schmadel had carried out on the earlier version. It was generally agreed that the thesaurus should be made available on computer disc, either instead of or as well as in printed form. It is hoped that journal editors will then use the thesaurus to select the terms to be used in their indexes. The thesaurus is being translated into French, Italian and Spanish by interested 
librarians. A German translation may also be be made. The Commission is greatly indebted to Robyn Shobbrook for the very considerable effort that she has devoted to this task; the support of the Anglo-Australian Observatory is also gratefully acknowl edged.

4. Classification systems. G. Wilkins expressed his regrets that the Task Group on the Revision of UDC 52 had as yet been not made any contribution to the revision of the classification schedule for astronomy; he hoped that proposals for the revision would be made during the coming year. A table of the relationship between the PHYS $(=$ PACS) and AAA classification systems has been completed and is given in AAA 1990 (52A).

5. Other matters. The object designation 1 ist used for AAA and PHYS has been enlarged, but it has not yet been reviewed by the Working Group on designations. $P$. Dubois pointed out that there is a longer list of catalogue designations on-line at the Strasbourg CDS.

The first volume of the multilingual Space Sciences Dictionary that is being prepared by J. Kleczek has been published by Elsevier; it deals with radiation and matter.

J. M. Watson has prepared a survey of 'Astronomical bibliography from commercial databases'; it has been published with many other relevant papers in Databases \& on-line data in astronomy, edited by M. A. Albrecht \& Daniel Egret, and publ ished by Kluwer (1991).

The meeting concluded with review by M. Kurtz of the status of NASA's Astrophysics Data System (ADS), which is primarily intended to allow remote use of many numerical databases with a common user interface, and of an associated project (now called STELAR) to explore the use of electronic means for improving access to the literature of astronomy. M. Albrecht pointed out ESA's European Space Information System (ESIS) will be similar to ADS.

Session 7.

30 July 1991

$9.00-10.20$

ASTRONOMICAL LIBRARIES

Chairman: W. H. Warren

1. Preliminaries. The Chairman of the Working Group on Astronomical Libraries, W. H. Warren, stated that the Group had been set up as result of the discussions at Washington and Baltimore in 1988.

The President of Commission 5, G. A. Wilkins, was invited to comment on how the Group could influence the IAU. He first reviewed the background and pointed out that there was already a great deal of cooperation betwen the librarians themselves, especially through the PAM-Group of the Special Libraries Association (SLA) and the European Group of Astronomy Librarians (EGAL). The main objective of the Group should be to foster greater cooperation between librarians and astronomers at both local and international levels. [In particular, there is now of ten only a poor exchange of information between them about changes in astronomical practices and requirements and about new developments in information processing techniques. As a consequence, the expertise of the librarians and the resources of the libraries are of ten under-utilised.] The Group could publicise its activities through reports in the IAU Information Bulletin, and it could write on particular issues to the IAU Executive Committee or to individual directors. Very few librarians are able to attend IAU General Assemblies and so the Group could also consider arranging another colloquium with the aim of involving a good mix of astronomers, database experts and librarians in the discussions. The attendance at the session (over 30, from 17 countries, but of whom only about 5 were members of Commission 5 and only 3 were librarians) showed the breadth of the interest in these matters. 
2. Reports and comments on activities. Brenda Corbin and others reported on some current activities, some of which are mentioned in the reports of other sessions.

A second edition of the Union List of Astronomy Serials is in preparation by $\mathrm{J}$. Bausch; it will contain information from at least 41 libraries in 7 countries, but more contributions, especially from Europe, would be welcomed.

An e-mail service, known as ASTROLIB and giving information and requests, is provided by Ellen Bouton from NRAO. Items for distribution should be sent to her (1ibrary@nrao.edu). The astronomers present were encouraged to send her information about new data products that might be of general interest. They were also requested to draw the attention of their librarians to the 'twinning programme' organised by M. Cummins (University of Toronto).

There were also complaints that the prices of IAU publications are very high with that the result that some libraries cannot afford to buy them. It was pointed out that the IAU received high royalty payments, and that in recent years the US dollar had depreciated considerably against the Dutch guilder.

Joint Meeting of Commissions $5 \& 6$

ELECTRONIC MAIL \& COMPUTER SOFTWARE

Co-chairmen: E. Roemer \& G. A. Wilkins

1. Preliminaries. The meeting first dealt with some items of business of Commission 6. It was also reported that the new chairman of the Commission 5 Working Group on Computer Communications and Astronomical Sof tware is K. Turner. The total attendance was over 40 , of whom only about one-third were members of Commissions 5 or 6 .

2. Electronic mail. B. G. Marsden, Director of the IAU Central Bureau for Astronomical Telegrams, opened the discussion by referring to the increasing use of e-mail for the distribution of IAU 'telegrams' and to the problems that were encountered, especially those resulting from the current lack of automatic transfers from one network to another and from the lack of standardisation in the forms of addresses. One specific recommendation that received general approval is that all astronomical institutions should have a username POSTMASTER, and should arrange to forward mail promptly to the person named in the message. There was also general agreement that the international e-mail directory produced by $C$. $R$. Benn and R. Martin at the Royal Greenwich Observatory is extremely useful, and that every effort should be made to ensure its continued maintenance, extension (by, for example, the inclusion of the addresses of AAS members) and distribution. Information on addresses, changes in networks, etc should be sent to Benn or Turner. It was suggested that the directory should also give FAX addresses, since although this system is of ten expensive it is useful for some purposes, such as sending graphical information.

3. Astronomical software. Turner stated that he will endeavour to update and extend the directory of astronomical software that had been started by Benn, and he requested that others help him by drawing his attention to the availability of suitable software. P. Linde drew attention to the world-wide non-commercial electronic bulletin board known as USENET. It contains many special ist newsgroups, of which SCI.ASTRO and SCI.SPACE are of interest to professional astronomers even though much of the material is contributed by amateurs. It would be feasible to create a special newsgroup for astronomical software, and D. Wells has recently created a new group, ALT.SCI.ASTRO.FITS to dicuss issues related to the FITS standards. Attention was drawn to the problems of distributing software by e-mail, but it was generally felt that the main effort should be devoted to the development of the directory, and that for the time being the programs and documentation could be distributed on tape or disc by ordinary post. 